\title{
Integrating climate-related stressor effects on marine organisms: unifying principles linking molecule to ecosystem-level changes
}

\author{
Hans-O. Pörtner* \\ Integrative Ecophysiology, Alfred-Wegener-Institute, Am Handelshafen 12, 27570 Bremerhaven, Germany
}

\begin{abstract}
Climate change effects on marine ecosystems involve various stressors, predominantly temperature, hypoxia and $\mathrm{CO}_{2}$, all of which may combine with further anthropogenic stressors such as pollutants. All life forms respond to these drivers, following potentially common principles, which are insufficiently understood. Specific understanding may be most advanced in animals where the concept of 'oxygen and capacity dependent thermal tolerance' (OCLTT) is an integrator of various effects, linking molecular to ecosystem levels of biological organisation. Recent studies confirm OCLTT involvement in the field, causing changes in species abundance, biogeographical ranges, phenology and species predominance. At the wholeanimal level, performance capacity set by aerobic scope and energy budget, building on baseline energy turnover, links fitness (within a thermal window) and functioning at the ecosystem level. In variable environments like the intertidal zone, animals also exploit their capacity for passive tolerance. While presently the temperature signal appears predominant in the field, effects may well involve other stressors, acting synergistically by narrowing the aerobic OCLTT window. Recent findings support the OCLTT concept as a common physiological basis linking apparently disjunct effects of ocean warming, acidification and hypoxia in a so-called climate syndrome. In brief, warming-induced $\mathrm{CO}_{2}$ accumulation in body fluids links to the effects of ocean acidification mediated by the weak acid distribution of $\mathrm{CO}_{2}$. Temperature-induced hypoxemia links to the hypoxia sensitivity of thermal tolerance. Future work will need to develop proxies for the temperature-dependent effects of climate-related stressors and also identify the principles operative in organisms other than animals and their underlying mechanisms. Mechanism-based modelling efforts are then needed to develop reliable organism to ecosystem projections of future change.
\end{abstract}

KEY WORDS: Ocean warming $\cdot$ Hypoxia $\cdot$ Acidification $\cdot$ Climate change $\cdot$ Ecosystem change Aerobic scope $\cdot$ Energy budget $\cdot$ Mechanism-based projections

\section{INTRODUCTION}

Climate change effects on marine ecosystems are investigated by marine researchers from various, apparently disconnected angles. Empirical studies have repeatedly elaborated effects on global and regional scales (e.g. Perry et al. 2005) and have led to projections of change adopting principles like temperature-dependent biogeography or body size (Che- ung et al. 2009, 2012). However, the respective cause and effect understanding (e.g. Pörtner et al. 2008) has not been fully integrated into such efforts. Benefits of such understanding are a high reliability and certainty of the knowledge and attribution of presently detected effects to climate change, and also a high certainty in the projection of future effects. Understanding cause and effect requires physiological knowledge of the mechanisms driving effect as 
well as knowledge of the reasons for their compulsory responses (trade-offs and constraints) under a set of environmental conditions. Lastly, these mechanisms require testing under field conditions so as to demonstrate their involvement and their role as leverage in causing ecological effects.

Quantitative evidence linking physiological phenomena to ecosystem-level processes and change is currently still scarce. Moreover, the number of concepts suitable to integrating and linking physiological with ecological phenomena is limited. In animals, relevance of physiological effects in a climate change context at the ecosystem level has only been demonstrated for the concept of 'oxygen and capacity dependent thermal tolerance' (OCLTT). The functional capacity of oxygen supply systems, especially of cardio-circulation, to fully match demand and sustain aerobic scope is limited to a thermal window characterized by its species- and life stage-specific setting and width on the temperature scale (Fig. 1). The principles of the OCLTT concept have been elaborated in representative species from various animal phyla: sipunculids, annelids, molluscs (bivalves, cephalopods), crustaceans and vertebrates (fishes). Recent evidence shows that the OCLTT principles likely also hold in air breathers relying on convective oxygen transport or in aquatic larvae of insects (Verberk \& Bilton 2011). These principles (see Pörtner 2001, 2002a, Pörtner et al. 2004a,b) have also been verified in larval stages of crustaceans (Storch et al. 2009) as well as in small zooplankton (Seidl et al. 2005). These observations tie in with a more general picture of how ambient oxygen levels shape and limit animal life through oxygen availability and the associated parameters (diffusion coefficient, concentration including gas solubility) of Fick's First Law of Diffusion. The capacity to supply oxygen is limited by the functional capacity of the circulatory system in fishes and invertebrates (Pörtner et al. 2004b, Somero 2012). Further limitation (in invertebrates) may involve the ventilatory system. In special cases, such as in adult crustaceans, ventilation of the egg masses is also limited by capacity (Cohen \& Strathmann 1996, Fernandez et al. 2000, Woods \& Moran 2008). The balance between oxygen supply and demand shapes the dependence of maximum body size in marine invertebrate phyla on temperature-dependent oxygen availability (Chapelle \& Peck 1999, Pörtner 2002b). These principles thus appear unifying in shaping the environmental border conditions of aquatic and possibly terrestrial animal life (Pörtner \& Farrell 2008). They may also help to understand the nature and changes in biotic interactions (competi- tion, predator-prey relationships) from the physiologies of interacting species (see below, Pörtner \& Farrell 2008, Pörtner 2010).

Applicability of the OCLTT concept to climate change questions would depend on its verification at the ecosystem level. Few studies have established such clear links between laboratory and field studies. Such field studies would report a climate-induced effect at the ecosystem level, and laboratory studies would establish the physiological reasons for such an effect (e.g. Anestis et al. 2007, 2008, Pörtner \& Knust 2007, Katsikatsou et al. 2012). Existing findings thus corroborate the applicability of the OCLTT concept. After its verification, this concept can also be used in the interpretation of field observations even when the underlying physiology has not (yet) been established. Nonetheless, further investigations still need to identify relevant details in the complex relationships between climate-dependent physiology and ecology. In this context, more traditional concepts require reinvestigation and, if possible, integration into OCLTT. For example, studies of thermal biology have often identified characters in isolation (such as critical thermal maxima or lethal limits) which are not directly but only distantly related to field observations or the effect of climate change. Studies may also have selected individual, e.g. cellular, stress indicators (Fig. 1B) which fit the context of OCLTT, but the whole organism aspects have not been included. Arrhenius slopes and break point temperatures studied at the whole-animal level frequently remained unexplained. Integration and interpretation of such findings in the OCLTT context is warranted and often feasible. While the identification and debate of mechanistic details are going on and group- or species-specific features or twists are being identified (e.g. Pörtner 2010, Eliason et al. 2011, Schulte et al. 2011), this does not question the general applicability of the OCLTT concept as supported by a rising number of field investigations.

Overall, the physiological processes underlying OCLTT shape the performance curve of a species, commonly exemplified in the temperature-dependent growth patterns observed. Oxygen limitation under warm conditions is predominantly caused by the limited capacity of the circulatory system to maintain aerobic scope despite rising baseline energy and thus oxygen demand reflected in the standard metabolic rate (SMR). Thermal limits can thus be shifted in two ways, by increasing or decreasing capacity and by increasing or decreasing SMR. Both capacity and SMR are interdependent such that limits result as a tradeoff between the two. 

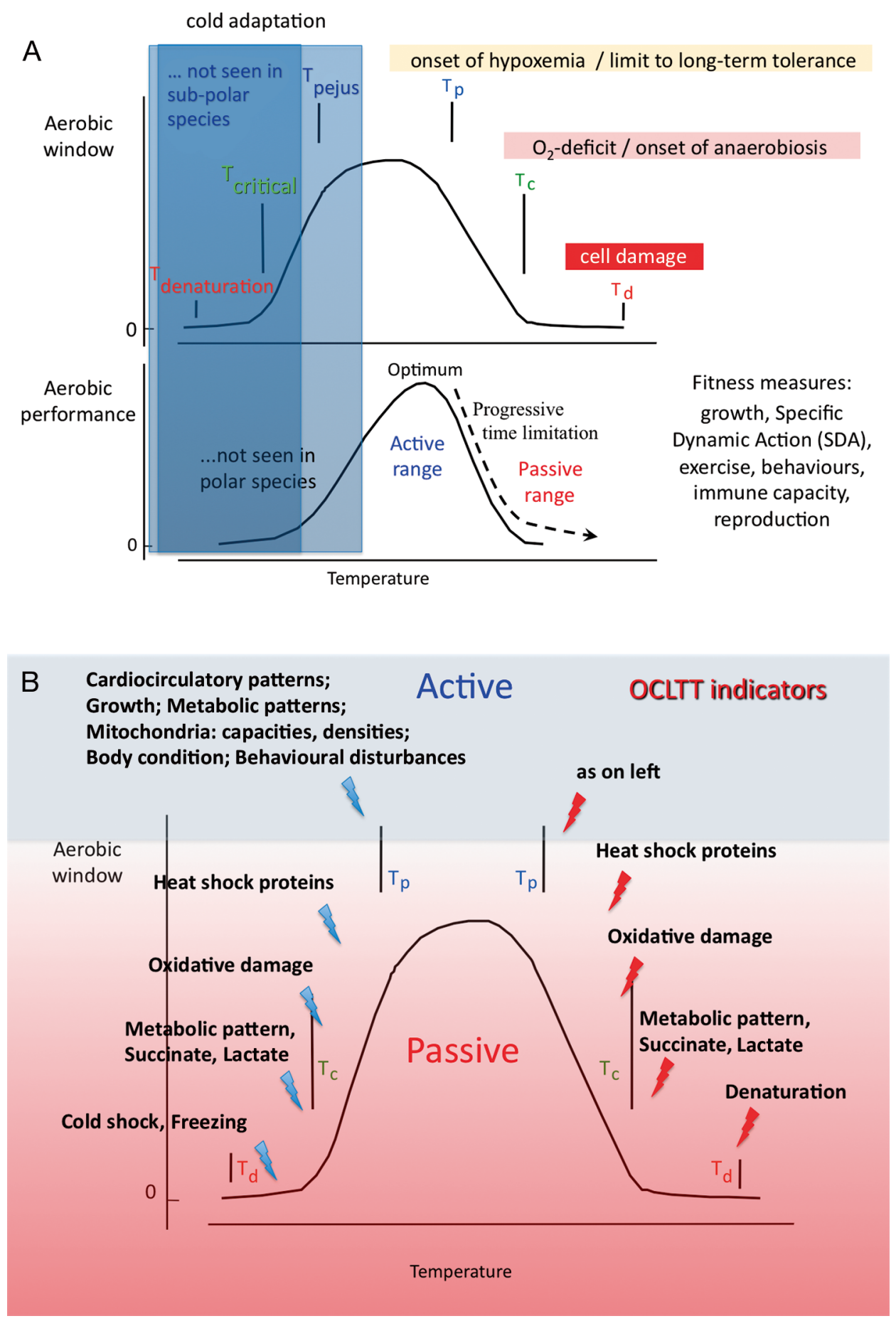

Fig. 1. OCLTT (Oxygen and capacity-limited thermal tolerance) as a concept integrating multiple stressors and various processes and their indicators (simplified from Pörtner 2010). (A) Limited thermal windows are set by (aerobic) performance capacity as the first level of thermal limitation. Optimized oxygen supply to tissues between low and high pejus temperatures (top) combined with the kinetic stimulation of performance rates by warming supports temperature-dependent performance and a functional optimum (i.e. an optimum of aerobic scope) close to upper pejus temperature. Note that in sub-polar and polar climates, due to falling oxygen demand and rising oxygen concentrations, the oxygen limitation of cold tolerance may not be seen, leaving a limitation through functional capacity (Wittmann et al. 2012). (B) According to the involvement of various physiological and biochemical processes in characterizing the various phases of thermal limitation, a set of parameters results which can be used as indicators of the thermal limitation process depending on temperature and over time. Note that the passive tolerance range is a relevant component of the niche in cases when organisms regularly experience extreme temperatures 
Depending on the climate regime studied, capacity limitation in the cold may or may not go hand in hand with oxygen limitation, as metabolic rate falls and high oxygen solubility in media and body fluids causes oxygen availability to be in excess under cold conditions. While oxygen deficiency in the cold develops in warm temperate species, it is alleviated in sub-polar and polar species (e.g. Wittmann et al. 2012, Fig. 1A). This review and position paper provides the most recent update on the OCLTT concept and extends to a treatment of its roles in understanding patterns of change in the field and how the mechanistic links between thermal tolerance and other factors relevant in climate change can be identified.

If alternative concepts exist that are equally powerful, similarities, differences and links to OCLTT would need to be clearly identified. However, I am presently not aware of concepts that would be equally as integrative as the OCLTT concept in animals. Some apparent alternatives can in fact be understood to emphasize various aspects that would be linked to OCLTT or where OCLTT would provide the links between the various approaches. Concepts clearly linking to the mechanistic framework of OCLTT include temperature-dependent reaction norms (Tewksbury et al. 2008), which mirror the level of aerobic scope in OCLTT (this paper). Long-term lethal limits (Peck et al. 2009) result from the exploitation of passive tolerance in OCLTT (Pörtner 2010). Thermal acclimatization and adaptation at transcriptomic and proteomic levels (Stillman 2003, Lucassen et al. 2006, Somero 2012, Tomanek 2012) link to associated shifts in pejus and critical tolerance limits (Pörtner et al. 2008). Studies of membrane or protein structure (Somero 2012) relate to whole-organism functional capacity at various temperatures and contribute to understanding how pejus and critical limits are set at the whole-organism level (Pörtner et al. 2012). Energy budgeting and efficiency (Sokolova et al. 2012) mirror the width and position of the thermal window on the temperature scale (Pörtner 2006). Changes in species interactions including predation and associated biodiversity changes (Harley 2011) may result from differential performance levels and their relative shifts in interacting species (Pörtner \& Farrell 2008, see below). In general, studies at molecular and biochemical levels can be interpreted to identify the foundation of functional capacity and thus OCLTT. It therefore seems that overall, concepts should be brought together more, rather than being presented as parallel alternatives.

\section{EVIDENCE LINKING OCLTT AND FIELD PHENOMENA}

\section{Fishes}

The examples discussed here all include field data and performance indicators, thereby linking to the OCLTT concept. First evidence for the concept being applicable to the ecosystem level came from a comparison of field and laboratory data in eelpout Zoarces viviparus from the German Wadden Sea (Pörtner \& Knust 2007). Summer extreme temperatures negatively affected population dynamics and caused a loss in the population, starting with the largest individuals. Laboratory studies confirmed that processes related to OCLTT, especially cardiocirculatory limitation and the allometry of oxygen limitation, explain these patterns. Onset of hypoxemia and capacity loss explains the loss of fitness upon warming and occurs in the largest individuals first. Reduced heat tolerance in larger specimens of a species suggests that especially spawners with their additional biomass of eggs and sperm are sensitive to warm temperatures (Pörtner et al. 2008). In Atlantic cod Gadus morhua, spawning may therefore occur in winter or early spring and even then, warming interferes, as indicated by the clear effect of winter warming on cod distribution (Perry et al. 2005). Early life stages may also be sensitive during the time when circulatory and ventilatory systems are not fully developed. On large latitudinal scales in the oceans, the pressure to thermally specialize may contribute to the strong differentiation of Atlantic cod into populations which specialize on the regional climate and display thermal windows different from each other, as a result of regional (i.e. local) adaptation (Pörtner et al. 2008). Local adaptation leads to genetically distinct natural populations of a species (Sanford \& Kelly 2011, Sotka 2012), possibly as a result of selection from a wide inter-individual geno- and phenotypic variability in the larval population.

OCLTT is also involved in constraining the spawning migrations of Pacific salmon in the Fraser River, BC, Canada (Farrell et al. 2008). The thermal limitation of swimming capacity in the warming river prevents adult spawners from reaching their upstream spawning grounds. Differences between stocks relate to differences in cardiac capacity and functioning (Eliason et al. 2011). Atlantic salmon Salmo salar or Pacific sockeye salmon Oncorhynchus nerka do not feed during spawning migrations (Doucett et al. 1999, Cooke et al. 2004). They thereby protect their aerobic scope from being compromised by the cost of 
food processing. This not only benefits their aerobic scope for swimming, but in light of OCLTT, this also maximizes their heat tolerance. However, the capacity to maximize exercise performance will be timelimited under these conditions, as high energetic demands will ultimately cause starvation and muscle wastage.

A study of the metabolic background of temperature-related tolerances in various age $(0+$ and $2+)$ and size groups of Atlantic salmon contributes to an understanding of how thermal limits relate to behavioural changes (Breau et al. 2011). A behavioural shift associated with aggregations in coldwater sites occurs in older and larger individuals $(2+)$ when warming drives their basal metabolic rate up to its maximum and leads to an accumulation of lactate, indicating that anaerobic pathways are recruited at beyond critical temperatures. This metabolic shift might be elicited by hypoxemia, which is thermally induced inside the organism. Lactate accumulation likely acts as an alarm signal, then causing behavioural hypothermia, a shift of preferred temperature to lower values (Pörtner et al. 1994).

In light of this progress in our understanding of cause and effect in climate change impact on organisms, any field data containing information on a performance term like growth or reproduction may also become explainable with OCLTTrelated hypotheses. Certainly, supporting such explanations would require laboratory investigations of the physiological background. An example emphasizing how thermal specialization explains sensitivity, productivity and large-scale ecological phenomena such as non-linear shifts in the species composition of ecosystems (regime shifts), is one of sardines and anchovies in the Japanese Sea. The thermal windows of growth and reproduction overlap in the 2 species but differ in their position on the temperature scale (Takasuka et al. 2007, 2008). This explains why warming caused anchovies to thrive and increase in abundance while sardine populations collapsed at the same time.

Specialization on regional climate associated with specific limits to thermal acclimation is also evident in field data on young banded morwong Cheilodactylus spectabilis and their growth and distribution in the Tasman
Sea (Australia, New Zealand). Growth data from otolith readings over the range of field temperatures according to the biogeography of the species yield the species-specific thermal performance curve (growth) (Neuheimer et al. 2011). On the cold side of the thermal window, left of the optimum, the data indicate a warming-induced increase in growth and a shift in distribution range, whereas beyond the thermal optimum, a warming-induced decrease in growth rate occurs reflecting the warm side of the performance curve (Fig. 2). Interestingly, field growth data falling on the warm side indicate that the species has some limited scope to reduce its temperature-dependent performance and to still persist in the ecosystem studied before performance levels become too low. At the species distribution boundary, warm acclimation would be expected to involve trade-offs in cellular and metabolic design and energy budget and allocation (cf. Pörtner \& Lannig 2009). Especially the down-regulation of mitochondrial densities and their maintenance costs under warm conditions may contribute to a lowering of SMR and, as a consequence, aerobic scope for growth with the benefit of enhanced heat tolerance. This also results through a reduction in maximum body size such that smaller individuals of a species are more heat tolerant and can persist in warmer waters (cf. Pörtner et

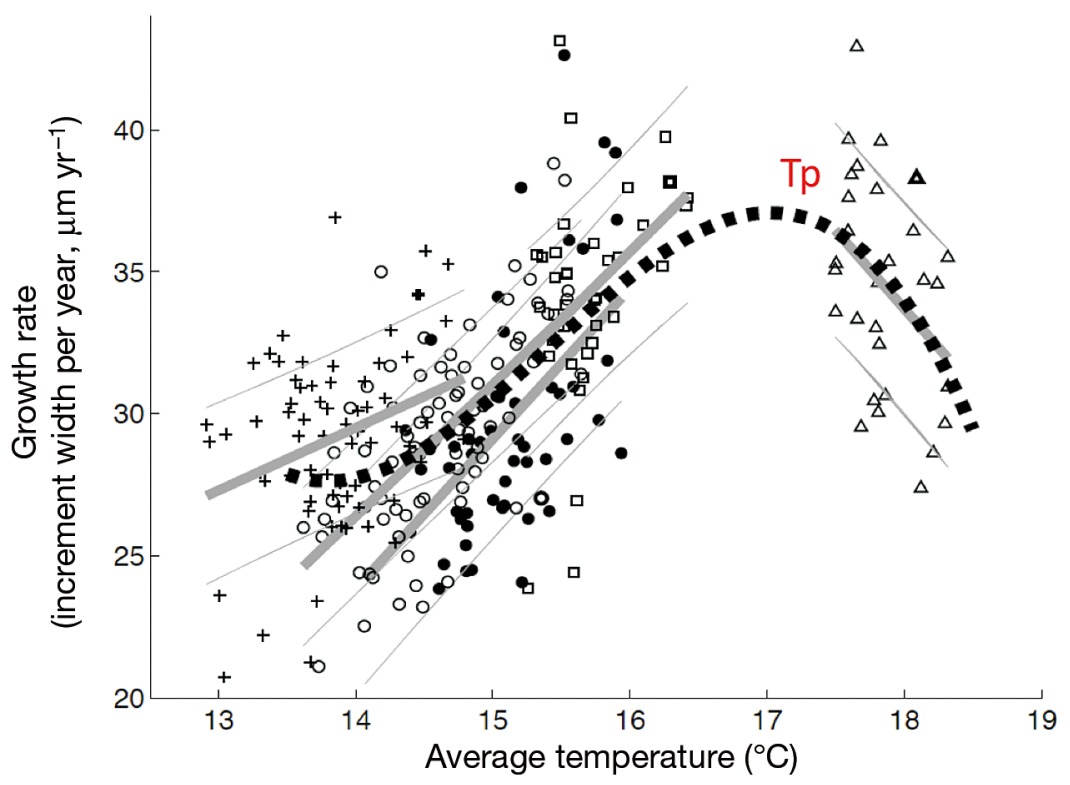

Fig. 2. Cheilodactylus spectabilis. Specialization on climate reflected by the thermal niche (limited by the capacity for acclimatization) according to growth rates from otolith readings in banded morwong around Australia and New Zealand in the field (after Neuheimer et al. 2011). Note the decrease in growth rates beyond apparent pejus limits under warm conditions, likely reflecting warm acclimatization, shifts of the acute thermal window and tradeoffs in energy budgets (see 'Evidence linking OCLTT and field phenomena' in the main text and Fig. 3). Tp: pejus temperature 
al. 2008). Recruitment from cooler waters may support such a pattern at distribution limits.

The examples discussed provide evidence that fishes experience their acute upper thermal limits of aerobic scope in the field. Aerobic scope fuels rates of growth as in benthic eelpout and banded morwong or swimming activity as in migrating salmon. These findings suggest that species operate in the field up to their specific limits of warm acclimation capacity. These environmental conditions represent those limiting the distribution limits of the species. In essence, all of these data emphasize the usefulness of interpreting data from well-controlled laboratory experiments in the context of environmental data from the field and vice versa.

\section{Coastal and intertidal invertebrates}

Further examples come from studies in the Mediterranean. Submersed mussels (Mytilus galloprovincialis, Modiolus barbatus) were observed and experimentally exposed to various temperatures in the lab and in the field (Anestis et al. 2007, 2008, Katsikatsou et al. 2012). Lab findings were compared to those gained in submersed mussels at field temperatures throughout the year. Field experiments transposed some animals to water depths with different temperature regimes. These studies in permanently submersed mussels exclude the complications introduced by air exposure in the intertidal zone and allowed the researchers to clearly identify those phenomena related to the seasonal temperature regime.

During summer heat as well as winter cold in the field, even these submersed mussels exploited the heat shock response (Anestis et al. 2007, 2008, Katsikatsou et al. 2012). These findings indicate that de- spite slow seasonal temperature change, animals reach the extreme ends of their thermal windows, beyond their thermal range of aerobic scope and in their passive range of thermal tolerance (extreme pejus and pessimum range, Fig. 1A). The range of ambient temperatures thus matches the thermal window, reflecting tight thermal specialization and limits to acclimatization capacity. Furthermore, the exploitation of the heat shock response indicates that vertical zonation of submersed mussels is co-determined by their capacity of time-limited passive resistance to temperature extremes. This indicates that these sessile species live where ambient temperatures periodically exceed the limits of sustained aerobic scope. These findings likely also relate to the capability of these mussels to thrive in intertidal habitats. Here, the southern distribution limits of intertidal mussels (Mytilus edulis) correlate with their lethal limits, an observation which also emphasizes that these mussels exploit their passive range of tolerance (Jones et al. 2009). Temperature, however, shapes distribution in the intertidal zone together with wave splash, emersion time and desiccation stress (Harley \& Helmuth 2003).

The capacity for acclimatization is likely very strong and the resulting shift in thermal window very wide in temperate zone species settling in the intertidal zone. Wittmann et al. (2008) and Schröer et al. (2009) demonstrated such shifts in the intertidal lugworm Arenicola marina according to season and climate zone. Such acclimatization capacity is reflected in the up-regulation of metabolic capacity upon cold exposure and the down-regulation of metabolic costs in warm conditions, such that residual aerobic scope remains sufficiently high. A thermal niche results, within which the acute thermal window shifts with acclimatization. The borders of the niche are characterized by the limits of acclimatization capacity (Fig. 3)
Fig. 3. The oxygen- and capacity-limited thermal tolerance (OCLTT) concept and its underlying mechanisms provide an understanding of performance shifts between seasons and the associated patterns of acclimatization, understood as a shift of acute thermal windows within the limits of the thermal niche (left, after Pörtner 2010) (see Fig. 2 legend). They also explain shifts in large-scale, temperature-dependent biogeography and climate sensitivity in the marine realm which involve a contraction of the available niche space on the warm side and a widening on the cold side of the temperature-dependent distribution range (center, after Beaugrand 2009). The temperature-dependent distribution range matches the thermal niche (right)

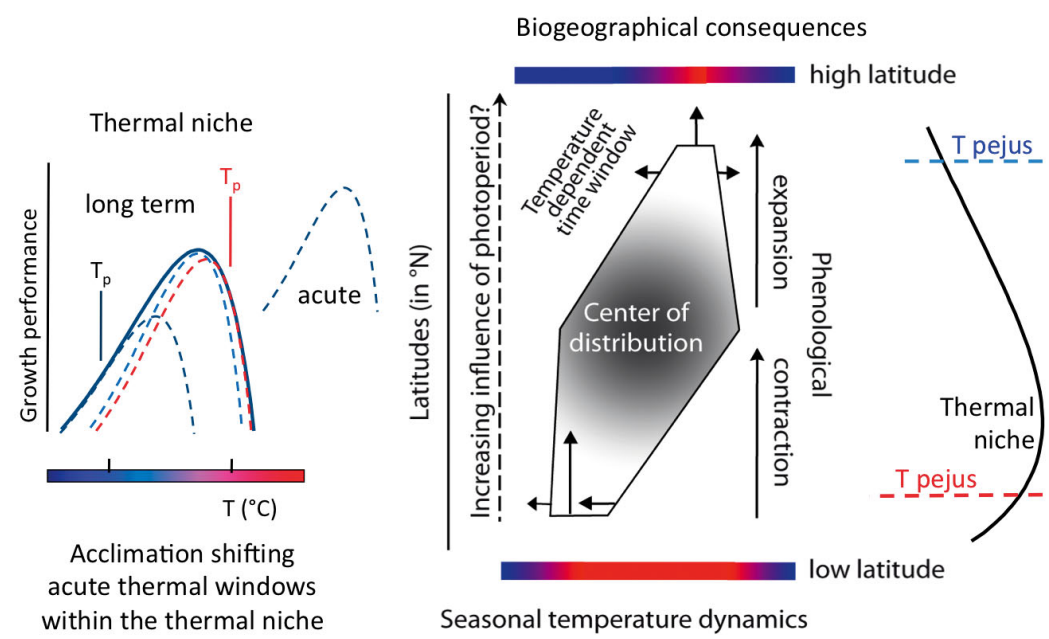


and would match the niche realized at the ecosystem level (cf. Pörtner et al. 2010). A recent study by Marshall et al. (2011) illustrates how intertidal snails (Echinolittorina malaccana) undergo acute acclimatization during low tide and down-regulate their metabolic costs acutely, upon warm exposure, possibly by exploiting strategies of metabolic depression when in air. The onset of the heat shock response is then delayed to a breakpoint temperature beyond which energy demand finally rises. These findings suggest that the down-regulation of metabolic costs under warm conditions may characterize the temperature range of constant metabolism of intertidal ectotherms already described by Newell (1969). The OCLTT concept would characterize this phase of apparent thermal insensitivity as the exploitation of a wide pejus range during which SMR remains constant upon warming. Aerobic scope becomes constrained and performance declines, but the transition to anaerobic metabolism is likely shifted to higher temperatures. The breakpoint temperature may in fact be equivalent to the critical temperature, which is characterized by the onset of anaerobic metabolism, in parallel to the onset of the heat shock response.

Phenomena seen on large latitudinal scales in the oceans are found on small scales in coastal and intertidal environments. Even within the intertidal zone, and similar to large-scale observations, local adaptation on small scales leads to genetically distinct natural populations of a species and plays an important role in governing survival and distribution patterns (Sanford \& Kelly 2011).

\section{Generalizations}

The examples of pelagic fish and coastal and intertidal invertebrates discussed here indicate that there are physiological limits to the realized niches of ectothermic species (Pörtner et al. 2010), which are associated with the limits of their acclimatization capacity (Stillman 2003). Acute thermal windows are narrower than this thermal niche, and the width and position of the acute window can shift widely with seasonal acclimatization (Fig. 3). Associated with this shift are shifts in baseline energy turnover and in aerobic scope as well as reallocations from the energy budget to crucial performances like growth, reproduction and behaviour. The comparison of ectotherms from various climates suggests that thermal specialization occurs for the sake of energy savings which are highest with narrow thermal windows in the permanent or seasonal cold (Pörtner 2006).
Intertidal and coastal species exploit the range of passive tolerance more than oceanic species, as a regular add-on to the acute thermal window (Fig. 1, not differentiated in Fig. 3). On shorter, e.g. diurnal, time scales in the intertidal zone, the exploitation of metabolic depression saves energetic cost. While this may contribute to aerobic scope reduction upon warming beyond pejus limits, it would cause an upward shift in critical temperature. Then, beyond critical limits, metabolic depression reduces the degree of anaerobic energy production and extends the time limits of passive tolerance (cf. Fig. 5).

Furthermore, it needs to be emphasized that the examples reported only take a snapshot glimpse out of the whole life cycle of a species. Thermal windows are dynamic and may change from the gamete through egg, embryo, larval, juvenile and adult stages to adult spawners (Pörtner \& Farrell 2008).

Providing cause and effect not only means linking ecological and physiological whole-organism phenomena but also means linking levels of biological organisation from ecosystem down to molecular and up. Unravelling the connections between levels of biological organisation, from genomic, molecular to cellular, individual and population levels, is crucial in understanding why organisms specialize on a limited range of environmental temperatures, and conversely, why and how the genomes and their intraspecific variability define the thermal sensitivity of species and their populations (cf. Kassahn et al. 2009). Scopes for acclimatization (phenotypic plasticity in physiology and behaviour) and adaptation (evolutionary shifts in morphology, physiology and behaviour) that together define species resilience require study at various life stages (eggs, larvae, juveniles, adults), as thermal windows as well as sensitivities to other factors vary between these stages.

The OCLTT concept has been proposed as a suitable umbrella integrating effects at various levels of biological organisation, from genome via molecular, cellular, whole organism to ecosystem (Pörtner 2002a, 2010). It thereby allows integrating phenomena that have been reported for one organisational level in isolation (e.g. heat shock protein expression or proteomics in general) and can now be re-interpreted in a larger context. For example, thermal specialization and associated energy savings in Antarctic stenotherms, largely exemplified in fish, typically involve reduced aerobic and anaerobic capacity, large myocytes with low capacities for ion exchange, the use of lipid body stores for low-cost neutral buoyancy and low-cost oxygen distribution by diffusion due to high density of lipid membranes. Excess oxygen availabil- 
ity at high oxygen solubility and low metabolic rates in the cold allow for the loss of haemoglobin and even myoglobin in some icefishes and the loss of the heat shock response in notothenioid fishes in general (for review see Pörtner et al. 2007, 2011). The other side of the coin of such adaptations is a high sensitivity to heat exposure, which in fact correlates with blood haemoglobin content (haematocrit) of Antarctic fishes, thereby reconfirming applicability of the OCLTT concept to Antarctic species (Beers \& Sidell 2011).

As a corollary, specialization on temperature likely supports maximized energy efficiency. Efficiency results from trade-offs at several hierarchical levels, from molecular structure to whole-organism functioning. For aerobic scope to be available requires staying within the aerobic thermal window; however, this may not be possible and thus may be discontinuous in some cases such as in the intertidal. Allocation of a sufficient fraction of time to staying within the aerobic temperature range appears obligatory for the sustenance of fitness and crucial life history phases (Pincebourde et al. 2008, Marshall et al. 2011 as reinterpreted here). The intervals of passive tolerance do not support growth or reproduction. Thermal stress thus causes performance losses, associated with hypoxemia and capacity limitations in warm conditions, and capacity limitations (associated with hypoxemia or not) at the cold end of the thermal envelope. The range of passive tolerance is regularly exploited in intertidal species and involves systemic and cellular stress signals like hormonal responses or oxidative stress. Stress protection is provided by mechanisms like metabolic depression, antioxidative defence or the expression of heat shock proteins. All of these indicators find their place and represent relevant components in the OCLTT window concept (Fig. 1B, cf. Fig. 5). Thermal acclimatization or adaptation cause thermal windows to shift, to change their widths or to adjust the shape of the performance curve. This happens between seasons or during adaptation to a climate regime or during local adaptation to variable local conditions.

\section{BEST PRACTICE APPROACHES}

Application of the OCLTT concept to various examples from diverse marine habitats leads one to ask about the best practice of its application, especially when it is applied by scientists from various disciplines, in this case either physiologists or ecologists. Each scientist may do this from different, apparently disconnected angles. The examples selected here indicate recent twists in the application of the concept and also the consequences once the relevance of integration is ignored.

A crucial aspect, which requires careful implementation with respect to the OCLTT concept, is the most appropriate way to test aerobic scope. This is best done by investigating the scope for aerobic performances like growth, or locomotion in steady state, including steady-state swimming or repeated spontaneous, non-stressful activities, and possibly reproductive output. These performances are those displayed by the species in nature but to various degrees, depending on the season and, most importantly, depending on its mode of life. A key element should therefore be the careful consideration of species-specific functional characteristics. For example, in highly mobile pelagic species, exercise is fuelled aerobically up to very high steady-state exercise levels, until anaerobic metabolism kicks in above critical swimming speeds (Pörtner 2002b, Lurman et al. 2007). Transition to functional anaerobiosis should be avoided in assays determining OCLTT, as stress hormones will become involved and push for non-steady state performance or affect limiting thresholds. Maximum aerobic metabolic rate can have an anaerobic component and would then be less suitable.

More sluggish demersal and benthic species display a smaller aerobic scope for exercise or do not display a capacity for continuous exercise at all. In extreme cases such as infaunal species, locomotion is mostly fuelled anaerobically, and not suitable as an indicator of aerobic scope. The resulting thermal window and optimum would apply for anaerobic metabolism and must not be the same as for aerobic metabolism. Furthermore, if experimental conditions place animals outside their preferred modes of behaviour or performance, a stress response may result, leading to unfavourable feedback on the parameters to be tested. As a corollary, aerobic scope should be tested as close as possible to the living conditions and behaviours seen in the natural habitat of the species.

Another key facet and potential dilemma involved in studying such a concept is the human factor. Individual scientists may be motivated to add their own twists to the interpretation of an overarching concept or to focus on selected aspects without being aware of relevant implications and their own biases. This may have the consequences of being too reductionist or of testing and discussing these selected aspects out of comprehensive context. Erroneous conclusions and misleading implications may result. Comprehensive testing of an overarching concept such as OCLTT in relevant case studies is important. Also, 
research needs to address the question of how to best integrate new findings. Such an approach would then also allow discovering new and relevant aspects and thereby developing the concept further.

The recent case study by Marshall et al. (2011) tested the OCLTT concept in littorinid intertidal snails. Their findings can successfully be integrated, with no need to classify them as being 'in contrast' to existing theory. In fact, their paper concludes that metabolic resting rate per se is important in shaping thermal tolerance. The principle role of resting or standard metabolic rate (SMR) is in fact a relevant component of the OCLTT concept. A low SMR in the thermal optimum characterizes sluggish species like the intertidal snail which exploits metabolic depression and passive tolerance more than active species. In contrast, a high SMR in the thermal optimum characterizes highly mobile, energetic species and supports high net aerobic scope as seen for example in squids or active teleosts. Due to high energy demand, their capacity for passive tolerance is extremely limited.

In general, if baseline oxygen demand or SMR rises from the thermal optimum to beyond upper pejus and then to critical limits, this indicates the development of constraints on aerobic scope. During temperature change, the adjustment of such resting rates thus is an integral part of the warm-acclimation process. This involves the down-regulation of mitochondrial cost (through proton leakage) and capacity as well as cost savings at the level of the cellular membrane. Thereby, the otherwise limiting increment of cost and associated SMR in warm conditions can be delayed and occur at higher temperatures. However, this likely occurs at the expense of aerobic scope such that the down-regulation of resting rate will also cause down-regulation of maximum aerobic metabolic rate (see Fig. 5). The key issue is that processes are intertwined between levels of biological organisation and between functional states. Looking at a level or process in isolation may be misleading with respect to how the full picture and the associated trade-offs develop. Specific modes of life as in the intertidal zone may include interesting modifications of individual processes contributing to OCLTT but not to the extent that alternative concepts are needed. The example of the banded morwong (Fig. 2) indicates that acclimatization or evolutionary adaptation to warm temperatures would not necessarily lead to beneficial acclimation in terms of maximized performance, but the decrease in growth seen in warm conditions likely results from trade-offs between all performances undertaken and/or from a decrease in maximum performance achieved in terms of aerobic energy turnover (see above).

\section{ROLE OF HABITAT CHARACTERISTICS: MULTIPLE FACTORS}

Experimental biology has traditionally focused on analysing responses to one environmental factor at a time and has treated the responding processes and mechanisms in isolation. However, palaeo- and ongoing climate changes involve changes and effects of various factors, making it difficult to disentangle the overall response and attribute elements thereof to individual factors. As a precondition, a comprehensive understanding of the full response of organisms to environmental change will only be possible from an integrative understanding of the interaction between factors and the synergistic, additive or antagonistic nature of effects.

Variability of environmental factors, especially temperature, differs between habitats. In the open ocean, temperature changes develop together with progressive hypoxia caused by enhanced stratification and oxygen demand of warming oceans (Stramma et al. 2008). Progressive carbon dioxide accumulation leads to ocean acidification, the degree of which depends on emission scenarios (Caldeira \& Wickett 2005, Cao \& Caldeira 2008). At increasing depths, the anthropogenic $\mathrm{CO}_{2}$ signal adds to already enhanced $\mathrm{CO}_{2}$ levels originating from microbial respiration of organic matter, which leads to the development of oxygen minimum zones (Brewer \& Peltzer 2009, Brewer 2009, Hofmann et al. 2011). The stochastic occurrence of extreme changes in any of these factors would exacerbate the effects of these progressive trends. However, this projection may be premature, as variability may have positive feedbacks on resistance (hardening). Regular extremes in temperature, hypoxia and hypercapnia characterize the seasonal and diurnal variability in intertidal zones.

Beyond changes in temperature, $\mathrm{CO}_{2}$ and hypoxia levels, salinity may change due to freshening of surface layers during enhanced river runoff or during ice melt in Arctic oceans (Denman et al. 2011). In coastal areas, pollution, e.g. by heavy metals, may interact with the other factors (Lannig et al. 2008, Sokolova \& Lannig 2008). For an integration of effects of various environmental factors, the concepts elaborated for the effects of individual factors should merge, preferably on a common denominator. As a basis for such integration, temperature, hypoxia and 
$\mathrm{CO}_{2}$ all affect energy turnover in relation to oxygen supply and demand. Temperature is the most ubiquitous, overarching and pervasive of these factors, as it shapes key characteristics of all marine life and ecosystems. For a comprehensive picture, it has therefore been suggested (Pörtner 2010) that temperature can be used as a matrix indicator such that the effects of the other factors occur on a landscape of temperature and its variability. Furthermore, interactions of the other factors with temperature change key temperature-dependent functions relevant for fitness and at the ecosystem level (see above). Therefore, the OCLTT concept has been proposed as a suitable integrator for specific effects of other climate-related stressors like ocean acidification and hypoxia or the effects of some pollutants (Pörtner 2010). Building on the causality emerging from such integration, the levels and changes of performance and resistance can be quantified. Such changes then provide a link between physiology and ecology and thus an understanding of ecosystem level processes as needed for realistic estimates and projections of species and ecosystem sensitivities to environmental change.

It needs to be emphasized that the aerobic window of an animal may not encompass the full range of temperature variability in its habitat, for reasons of energy efficiency or because temperature extremes coincide with other stressors like hypoxia, hampering the full use of aerobic scope. All of this would decide whether the aerobic performance window only, or the passive sections of the thermal window, are also regularly exploited (as in the intertidal zone). This would involve the use of wholeorganism to molecular mechanisms supporting passive tolerance (see Fig. 5). In the intertidal zone, especially during daytime heat exposure at low tide, oxygen deficiency may develop rapidly and regularly for some species, e.g. due to oxygen deficiency or emersion from sea water. Constraints on respiration cause $\mathrm{CO}_{2}$ to accumulate internally under such conditions. Animals then go into metabolic depression and with rising temperatures exploit the mechanisms of passive tolerance, by using anaerobic metabolism, the heat shock response and antioxidative defence mechanisms beyond critical temperatures. Use of these mechanisms and their species-specific capacities will extend the time period of survival (cf. Pörtner 2010) but would not involve activities like foraging and reproduction or performances like growth and, therefore, is time limited. Foraging, growth and reproduction would largely take place during high tide periods and within the aerobic window (see above).
Various other environmental factors like $\mathrm{CO}_{2}$ (ocean acidification), pollution or hypoxia are also subject to variability, partly depending on habitat characteristics like stratification or microbial oxygen demand or on the degree of anthropogenic influence, for example eutrophication. All of these pose additional stressors, which have been interpreted to constrain aerobic performance and fitness and narrow the thermal window. The scarcity of data suggests that $\mathrm{CO}_{2}$, hypoxia and heavy metals like cadmium display synergistic interactions with temperature at thermal extremes, whereas effects may be antagonistic in the central section of the thermal window. For example, warming from lower pejus temperature $\left(T_{p}\right)$ to the thermal optimum may aid ion exchange capacity and thereby improve $\mathrm{CO}_{2}$ resistance. Upon warming to higher than upper pejus and critical limits, however, aerobic scope and associated active $\mathrm{CO}_{2}$ resistance fall, as concluded from a downward shift of critical temperatures under elevated $\mathrm{CO}_{2} \mathrm{lev}$ els (Walther et al. 2009).

Hypoxia decreases oxygen availability and thereby causes a narrowing of thermal windows due to exacerbated body fluid hypoxemia. Similarly, $\mathrm{CO}_{2}$ accumulation causes a narrowing of thermal windows, likely through a $\mathrm{pH}$-induced decrease in tissue functional capacity, strongest at thermal extremes. Some pollutants cause an increase in SMR and, thereby, a downward shift in upper thermal limits. These processes function as links between the effects of individual factors as outlined below. Weak acid distribution of $\mathrm{CO}_{2}$ (Fig. 4) provides access to an integrated understanding of apparently disconnected effects of ocean acidification on whole-organism processes. Disturbances in acid-base status and differential acid-base regulation in various compartments lead to different levels of $\mathrm{pH}$, bicarbonate and carbonate and affect cellular, including neuronal, functioning or calcification, the latter set by the resulting calcium carbonate saturation at calcification sites (cf. Pörtner 2008). As an example, this principle mediates the correlation between calcification rates and calcium carbonate saturation levels in the water, the pattern of correlation being influenced by $\mathrm{pH}$ compensation capacity (e.g. McCulloch et al. 2012). Overall, hypoxia and $\mathrm{CO}_{2}$ constrain active tolerance to thermal extremes and rather stimulate the mechanisms supporting passive tolerance by enforcing metabolic depression (Fig. 5), for example via a decrease in body fluid $\mathrm{pH}$ or an accumulation of adenosine in nervous tissues (Reipschläger \& Pörtner 1996, Reipschläger et al. 1997, Pörtner et al. 2000). This may be useful for extending passive tolerance periods as in 
Fig. 4. Consideration of weak acid distribution of $\mathrm{CO}_{2}$ leads to an integrated understanding of apparently disconnected effects of ocean acidification on whole organism processes like (A) cellular, including neuronal, functioning or (B) calcification at internal sites, elicited via disturbances and compensatory adjustments in acid-base status. In (B), the correlative relationship between water properties and compartmental effects depends on the capacity for $\mathrm{pH}$ regulation associated with the compensation of compartmental $\mathrm{pH}$ disturbances mediated by increasing bicarbonate levels •-fold. Carbonates are formed depending on bicarbonate concentration and the dissociation constant of bicarbonate $\mathrm{pK}_{2}{ }^{\prime}$, in relation to the $\mathrm{pH}$ reached. Omega $(\Omega)$ is also heavily influenced by the level of calcium set in various compartments. Note the amplification of carbonate levels and calcium carbonate saturation resulting at calcification sites (factorial ion ratios [black dots] across compartmental barriers are valid for marine invertebrates, assuming similar calcium levels across extracellular compartments and in water). $\alpha$ : solubility coefficient for $\mathrm{CO}_{2}$. Note that the depiction of ion exchange mechanisms is incomplete

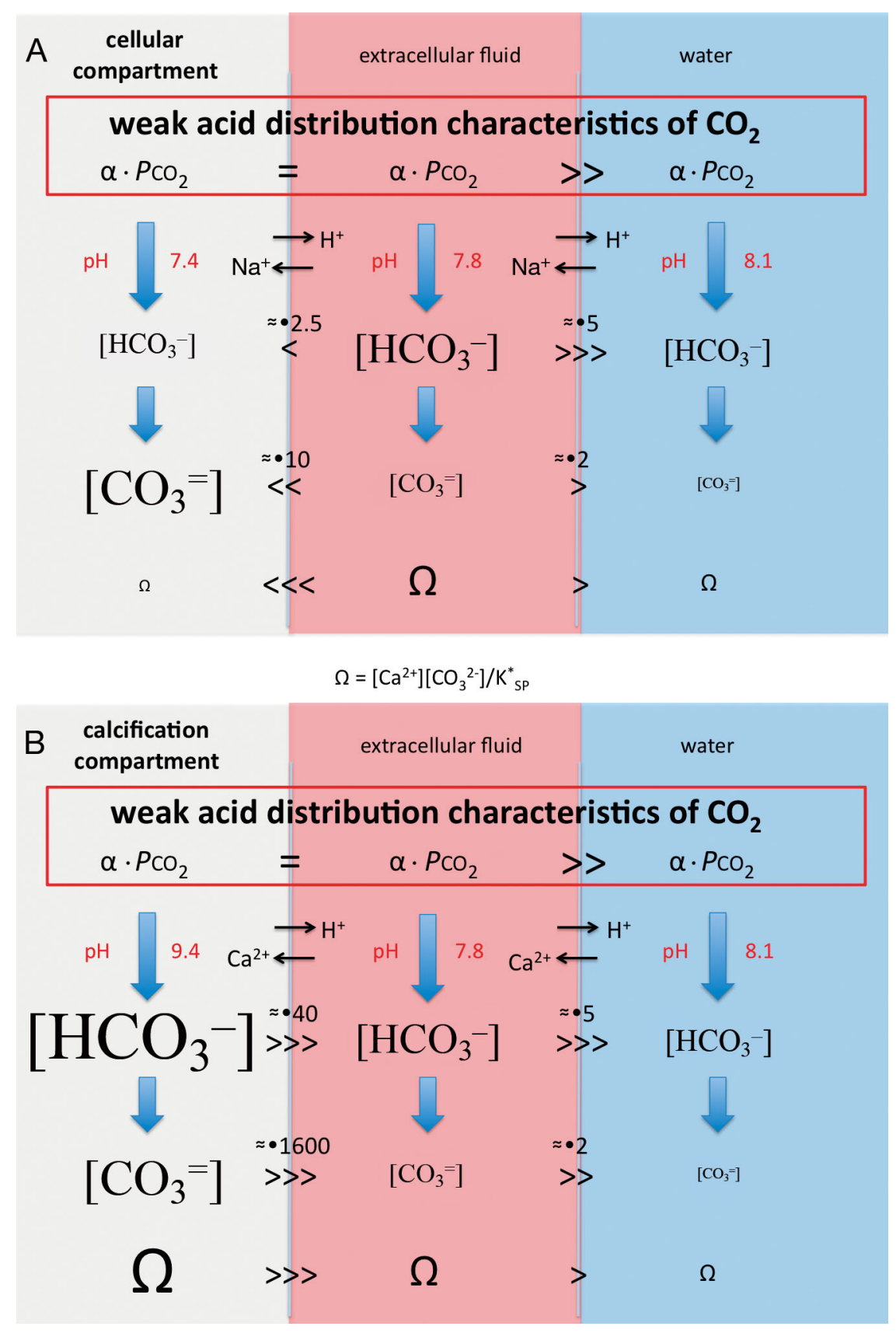

the intertidal. The dimensions of the thermal windows thus appear flexible, not only due to acclimation or local adaptation under a changing seasonal temperature regime but also in response to acute and progressive (climate related) stressor effects (shifting regimes of temperature, hypoxia, $\mathrm{CO}_{2}$, biotic stressors). This flexibility and the mechanisms used are covered by the OCLTT concept in animals as outlined above. Certainly, further research needs to complement the details such as the chain of signalling events. Again it remains to be explored whether the associated principles may also work for organisms other than animals, based on similar or specific sets of mechanisms.

Recent examples that confirm the hypothesis of a narrowing thermal window under the effect of additional stressors (Pörtner \& Farrell 2008, Pörtner 2010) in lab and field studies include $\mathrm{CO}_{2}$ effects on thermal limits in crustaceans (Metzger et al. 2007, Walther et al. 2009, Findlay et al. 2010), on aerobic scope at thermal limits in fishes (Munday et al. 2009) and on performance under thermal extremes in 


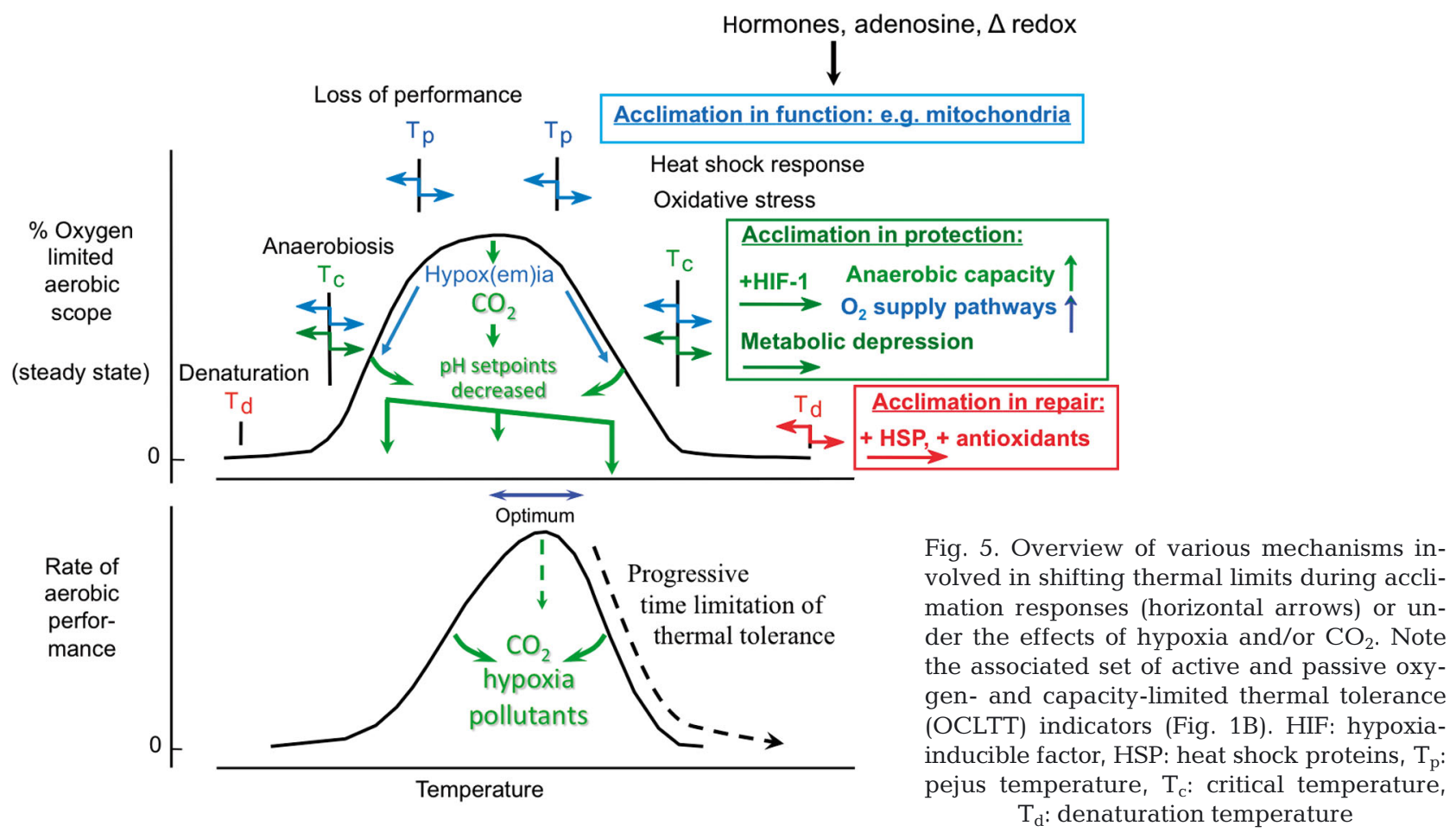

corals (via $\mathrm{CO}_{2}$-enhanced bleaching, Anthony et al. 2008). In a climate change scenario, with thermal tolerance likely limited and not sufficiently dynamic on relevant time scales, animals are then brought to the long-term edges of their thermal window earlier. Furthermore, $\mathrm{CO}_{2}$ sensitivity is thermally enhanced such that warming oceans combined with progressive $\mathrm{CO}_{2}$ accumulation would lead to an earlier effect of $\mathrm{CO}_{2}$. At the borders of the thermal envelope, hypoxemia and associated $\mathrm{CO}_{2}$ accumulation in body fluids would exacerbate the stress response. These aspects of enhanced sensitivity to $\mathrm{CO}_{2}$ remain insufficiently explored in organisms from all climate zones.

Evidence for changes in the field induced by anthropogenic $\mathrm{CO}_{2}$ is largely lacking for extant marine ecosystems, possibly because specific effects of $\mathrm{CO}_{2}$ on marine ecosystems may still be small. A decrease in calcification rates has been observed in some coral reefs (De'ath et al. 2009); however, this observation likely includes stressful effects of ocean warming, which has repeatedly elicited bleaching and consequently a decrease in coral cover starting in the late 1970 s to early 1980s. Elevated $\mathrm{CO}_{2}$ tensions were found to enhance the bleaching response (Anthony et al. 2008), but the contribution of $\mathrm{CO}_{2}$ to the present trends of decreased calcification has not been quantified. Nonetheless, the performance principles of the OCLTT concept also seem applicable to the special case of reef corals and will in the future likely include effects of rising ambient $\mathrm{CO}_{2}$ levels.
The width of the thermal window is crucial in this context. It has been hypothesized that it is wider in animals displaying high resting metabolic rates (in the thermal optimum) and high functional capacities of activity and associated metabolic pathways. These features are displayed by animals exposed to high climate variability in (sub-)polar areas like the (sub-) Arctic (Pörtner 2006). Within an ecosystem, these features are also displayed by the more agile species. Animals with an elevated SMR are also those possessing a high capacity in acid-base regulation to handle respiratory $\mathrm{CO}_{2}$ accumulation and anaerobic metabolic disturbances of acid-base status once energy demand increases beyond aerobic metabolic rates. These patterns would be associated with high levels of aerobic scope and energy turnover as seen in active compared to sluggish species in general, or in sub-Arctic species or populations compared to their temperate relatives. This differentiation may be the result of local adaptation from within-species genetic variability, which then also influences sensitivity to ocean acidification. Variable responses to $\mathrm{CO}_{2}$ may result within the thermal optimum and thus reflect species- or population-specific $\mathrm{CO}_{2}$ sensitivities in accordance with metabolic capacity. Sensitivity is likely higher overall at the edges of the thermal window but may also vary in a species-specific manner. Accordingly, variability between individuals would depend on where in the thermal window the response occurs. A resulting hypothesis to be tested 
by meta-analyses would be that both extended eurythermy and low sensitivity to ocean acidification may go hand in hand, in the same climate zone (according to active versus sluggish mode of life) and when comparing related species or their populations from various climates. Such effects are likely strongest towards the cold end of the temperature scale (Pörtner 2004, 2006); however, examples from temperate zones with variable temperatures (such as in temperate continental seas, e.g. the Black Sea or the Mediterranean) need to be included in such comparisons.

The combined and synergistic effects of various stressors and the assessment of the overall sensitivities may in fact lead to a clearer distinction between functional groups and their response to climate change. Such categorization has been carried out by Knoll et al. (1996, 2007) and Knoll \& Fischer (2011), for the Permian Triassic mass extinction event, indicating an apparent role for $\mathrm{CO}_{2}$ in line with functional differentiations between affected groups. Contributions by other stressors have not been as prominent, although this phenomenon does not exclude the effects of other stressors. It may just be that among synergistic stressors, effects of ambient $\mathrm{CO}_{2}$ are only apparently selective between groups, for various reasons. Present evidence suggests that effects of extreme temperatures, hypoxia and $\mathrm{CO}_{2}$ develop synergistically; extreme temperatures also come with an inherent $\mathrm{CO}_{2}$ and hypox(em)ia effect (by causing hypoxemia and associated internal $\mathrm{CO}_{2}$ accumulation; Figs. 5 \& 6). $\mathrm{CO}_{2}$ effects on physiological processes like calcification (cf. Pörtner 2008) will likely also become involved under any condition causing $\mathrm{CO}_{2}$ to accumulate internally in the organism. Respiratory constraints at extreme temperatures or during hypoxic hypercapnic exposure in oxygen minimum zones or in the intertidal cause $\mathrm{CO}_{2}$ accumulation and associated acid-base disturbances eliciting metabolic depression (Pörtner 1982, Pörtner et al. 1998, Zittier et al. 2012; Fig. 6). Extreme temperatures at the edges of the thermal envelope in fact include effects on organismal physiology via hypoxemia and $\mathrm{CO}_{2}$ accumulation. Such integration easily illustrates that the synergistic interactions of ambient hypoxia and $\mathrm{CO}_{2}$ with extreme temperatures exacerbate any effects developing internally at higher temperatures and are essentially an exacerbation of OCLTT.

Temperature, hypoxia and $\mathrm{CO}_{2}$ signals can thus not easily be distinguished, as the temperature signal will strengthen the $\mathrm{CO}_{2}$ and hypoxia signals and vice versa. Sensitivity thresholds to ocean acidification (OA) will change depending on temperature and thermal limits; conversely, sensitivity thresholds to temperature will change depending on exposure to OA and hypoxia. Accordingly, while the fossil record witnesses a categorization according to OA effects, these would also develop under long-term temperature change and hypoxia and be most expressed once $\mathrm{OA}$, temperature extremes and hypoxia develop concomitantly. These considerations would explain observations where temperature extremes cause internal $\mathrm{CO}_{2}$ accumulation and, thereby, phenomena similar to those caused by OA (cf. De'ath et al. 2009). These concerns lead to the question of whether a climate-related syndrome should be defined which encompasses the effects of factors changing in a parallel or interdependent way in both the water and in body fluids (e.g. excess respiration causing hypoxia and hypercapnia in stratified or isolated water bodies, freshening exacerbating acidification, temperature extremes causing organismal hypoxemia and hypercapnia). These considerations emphasize that one of the clearest future impacts of OA will be the enhancement of sensitivity to temperature extremes (see above). Only when organisms are within their thermal optimum and have access to normoxic and normocapnic water will they have typically low internal $\mathrm{CO}_{2}$ levels, and only for organisms under these conditions are specific effects of anthropogenic OA conceivable (cf. Pörtner 2008). Under all other conditions, combined effects of various environmental factors are likely.

As a corollary, the responses of energy turnover and budget, tissue functional capacities and the width of thermal windows related to environmental stressors support an integrative understanding of specialization on climate and, on the other side of the coin, of sensitivity to climate-related factors under the framework of OCLTT.

\section{MICROBIAL ORGANISMS: BACTERIA AND PHYTOPLANKTON}

The same set of questions as relevant for animals would likely apply to microbial organisms. The comparison of thermal limits across organism kingdoms supports 2 hypotheses: (1) limits fall with increasing levels of organisational complexity between prokaryotes and metazoans and (2) limits are set at the highest levels of functional integration, e.g. circulation, ventilation and neural control in animals (Pörtner 2002a). Although maximum heat limits of some unicellular eukaryotic species are found above metazoan heat limits, ongoing warm- 


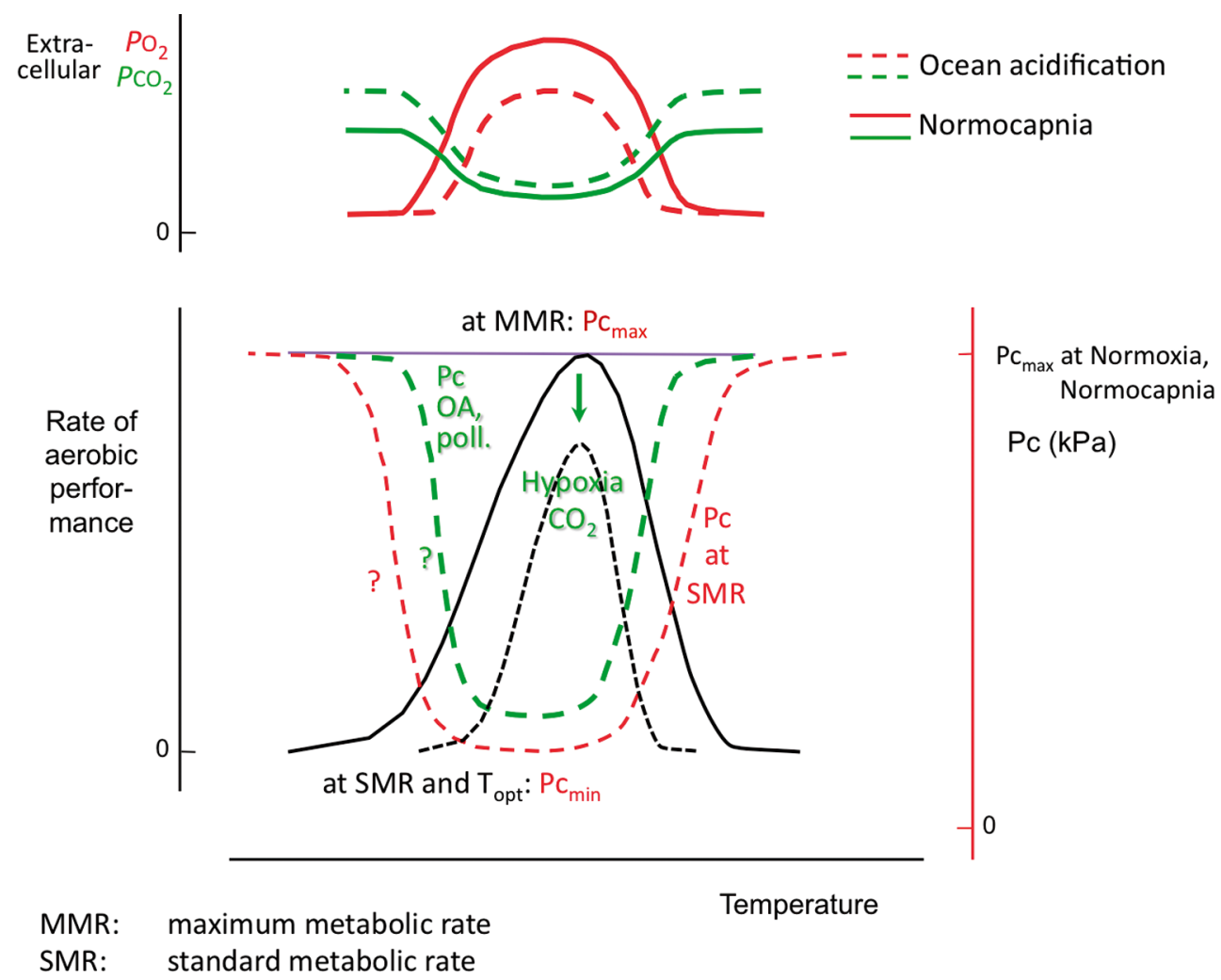

Fig. 6. Warming-induced hypoxemia and $\mathrm{CO}_{2}$ accumulation as well as changes in energy cost provide the principal links between synergistic effects of temperature, hypoxia, ocean acidification and pollutants (see 'Role of habitat characteristics: multiple factors') in a warm-temperate animal species (cf. Fig. 1). Ambient hypoxia acts via reducing systemic oxygen tensions, thereby causing an upward shift in critical oxygen tension, Pc (indicating earlier transition to anaerobic metabolism in hypoxia), reducing performance capacity and aerobic scope and eliciting a narrowing of thermal windows. Elevated ambient and, thereby, elevated internal $\mathrm{CO}_{2}$ levels according to weak acid distribution patterns and diffusion gradients (Fig. 4) also cause a narrowing of thermal windows. Once pH compensation remains insufficient at thermal extremes and, in some cases, in the active thermal range, lower functional capacities and reduced systemic oxygen tensions result, causing lower performance capacities. Such constraints are exacerbated by any increase in energy demand as elicited during exposure to pollutants (poll.) (expanded from Pörtner 2010)

ing causes shifts of eukaryotic phytoplankton to higher latitudes, thereby indicating lower heat limits and that large-scale biogeography of these organisms is also influenced by temperature (Thomas et al. 2012). Furthermore, the growth rates of phytoplankton and bacteria follow the typical shape of temperature-dependent performance curves or reaction norms (Eppley 1972, Ratkowsky et al. 1983). Accordingly, species succession in communities is possibly co-determined by differential thermal windows of species and their plastic responses to other factors like light and nutrient availability. In line with the present focus on animals, when addressing the impact of cold or warmth on complex cellular or organismal functions, it is important to consider that both heat and cold sensitivity are intertwined. It is also important to focus on where in the thermal window and on the performance curve effects of additional drivers are being looked at. At unicellular levels, suitable (highest) functions shaping thermal limits would be (in prokaryotes) metabolic complexes, e.g. in membranes. In unicellular eukaryotes, an additional or key element would be the coordination of function between subcellular compartments (cytosol, mitochondria, chloroplasts). Accordingly, photosynthetic capacity also follows such reaction norms (Claquin et al. 2008) and may well shape the thermal consequences for the whole organism. By disturbing $\mathrm{pH}$ setpoints and challenging $\mathrm{pH}$ regulation mechanisms (Taylor et al. 2012), OA may interact with temperature-dependent performances of unicellular algae in similar ways as outlined here for animals. Future research is needed to detail and complement this emerging picture. 


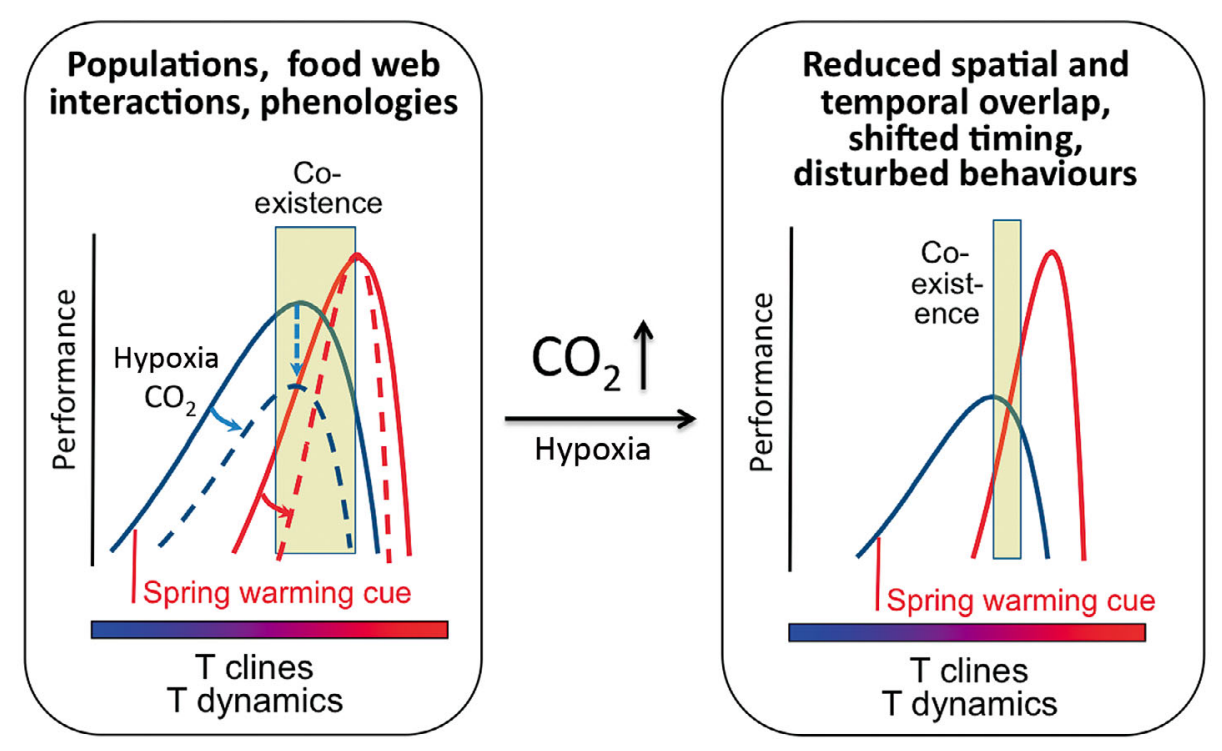

Fig. 7. Conceptual model of how species interactions are affected by the synergistic effects of shifting temperatures, elevated $\mathrm{CO}_{2}$ and exacerbating hypoxia levels (arrows, broken curves, left) on phenology and performance, at the ecosystem level (right). Depending on species-specific lifestyles and life stages, performance windows differ between species in an ecosystem where they show spatial (e.g. on latitudinal temperature clines, cf. Fig. 3) and temporal (e.g. during time-dependent, dynamic temperature changes) overlap. The model builds on a mechanistic understanding of how effects of hypoxia and $\mathrm{CO}_{2}$ on performance combine on a thermal matrix defined by the OCLTT principles (dashed lines, left) and shape differential changes in temperature-dependent performance, e.g. under elevated $\mathrm{CO}_{2}$ partial pressures (upward arrow in center) or hypoxia. Species-specific sensitivities and the resulting differential changes in performance define the range of temporal and spatial overlap of interacting species as well as their changes in interactions due to shifts in relative performance (modified from Pörtner \& Farrell 2008). These may involve changes in phenology, competition or susceptibility to predation

\section{THE NEXT LEVEL UP}

The question arises how to implement these conceptual developments, which firmly rest on an integrative understanding of existing data, into an ecosystem level understanding. Cheung et al. (2009) adopted the thermal window approach using climate envelope modelling and, based on the relationships between present temperature and distribution ranges, drew a picture of the projected climate-induced shifts in species distributions across wide latitudinal clines. The dynamics of the thermal window through interaction with other factors, through acclimatization or through local adaptation was not taken into account. Development of such a mechanism-based approach would enhance certainty in the simplified projections of biogeographical consequences at the species level.

Such projections remain simplified, because shifts in distribution, population dynamics and competiveness at the ecosystem level might include climateinduced changes in species interactions and thus, community responses at the ecosystem level. The productivity of a species, including its reproductive output and the growth rates of its various life stages, is determined by a complex set of factors. As a further complication, these factors may shift over time. This not only includes the seasonal changes of abiotic factors and their feedback on performance, but also biotic interactions. The latter have traditionally been viewed separately and as another complexity level; however, they should also be integrated into the present generalized picture. The relative phenology and performance of species would be crucial in this context. Availability of prey may differ over time and follow different optima from that of the predator (Fig. 7). This complexity may become accessible through knowledge of the performance curves of interacting species and their phenologies, which also define the temporal and thermal range of coexistence (Pörtner \& Farrell 2008). In line with differential thermal ranges of organism groups or functions (e.g. heterotrophic bacteria versus photoautotrophic phytoplankton), this may also extrapolate to a temperature-dependent shift in functions from photoautotrophs dominating at higher (cooler) latitudes to heterotrophic bacteria progressively dominating at lower (warmer) latitudes (Hoppe et al. 2002). At least for animals, the effects of various stressors can then be projected to affect the thermal range of coexistence and species interactions. 
Commercial exploitation of marine species also modulates these relationships and can be integrated as just another interacting species with variable predation (catch) efficiency and success. Any resulting changes in the population structure of predator or prey species would feed back on these relationships and thereby influence the sensitivity of marine ecosystems to climate change. It appears from these theoretical considerations that the OCLTT concept as calibrated against field phenomena and possibly developed into a mechanistic framework characterizing the climate syndrome provides a suitable framework for disentangling some of the complexities in these relationships at the ecosystem level.

Acknowledgements. This work is a contribution to the 'European Project on Ocean Acidification' (EPOCA), which received funding from the European Community's Seventh Framework Programme (FP7/2007-2012) under grant agreement no. 211384. It is also a contribution to the project 'Biological Impacts of Ocean Acidification' (BIOACID) funded by the German Ministry of Research and Education (BMBF).

\section{LITERATURE CITED}

Anestis A, Lazou A, Pörtner HO, Michaelidis B (2007) Behavioural, metabolic and molecular stress indicators in the marine bivalve Mytilus galloprovincialis during longterm acclimation at increasing ambient temperature. Am J Physiol 293:R911-R921

> Anestis A, Pörtner HO, Lazou A, Michaelidis B (2008) Metabolic and molecular stress responses of sublittoral bearded horse mussel Modiolus barbatus to warming sea water. Implications for vertical zonation. J Exp Biol 211: 2889-2898

> Anthony KRN, Kline DI, Diaz-Pulido G, Dove S, HoeghGuldberg O (2008) Ocean acidification causes bleaching and productivity loss in coral reef builders. Proc Natl Acad Sci USA 105:17442-17446

Beaugrand G (2009) Decadal changes in climate and ecosystems in the North Atlantic Ocean and adjacent seas. Deep-Sea Res II 56:656-673

> Beers JM, Sidell BD (2011) Thermal tolerance of Antarctic notothenioid fishes correlates with level of circulating hemoglobin. Physiol Biochem Zool 84:353-362

> Breau C, Cunjak RA, Peake SJ (2011) Behaviour during elevated water temperatures: Can physiology explain movement of juvenile Atlantic salmon to cool water? J Anim Ecol 80:844-853

> Brewer PG (2009) A changing ocean seen with clarity. Proc Natl Acad Sci USA 106:12213-12214

Brewer PG, Peltzer ET (2009) Limits to marine life. Science 324:347-348

Caldeira K, Wickett ME (2005) Ocean model predictions of chemistry changes from carbon dioxide emissions to the atmosphere and ocean. J Geophys Res 110:C09S04, doi: 10.1029/2004JC002671

> Cao L, Caldeira K (2008) Atmospheric $\mathrm{CO}_{2}$ stabilization and ocean acidification. Geophys Res Lett 35:L19609, doi: 10.1029/2008GL035072
Chapelle G, Peck LS (1999) Polar gigantism dictated by oxygen availability. Nature 399:114-115

Cheung WWL, Lam VWY, Sarmiento JL, Kearney K, Watson AJ, Pauly D (2009) Projecting global marine fish biodiversity impacts under climate change scenarios. Fish Fish 10:235-251

> Cheung WWL, Sarmiento JL, Dunne J, Frolicher TL and others (2012) Shrinking of fishes exacerbates impacts of global ocean changes on marine ecosystems. Nature Clim Change (in press), doi:10.1038/nclimate1691

Claquin P, Probert I, Lefebvre S, Veron B (2008) Effects of temperature on photosynthetic parameters and TEP production in eight species of marine microalgae. Aquat Microb Ecol 51:1-11

> Cohen SP, Strathmann RR (1996) Embryos as the edge of tolerance: effects of environment and structure of egg masses on supply of oxygen to embryos. Biol Bull (Woods Hole) 190:8-15

> Cooke SJ, Hinch SG, Farrell AP, Lapointe MF and others (2004) Abnormal migration timing and high en route mortality of sockeye salmon in the Fraser River, British Columbia. Fisheries 29:22-33

$>$ De'ath G, Lough JM, Fabricius KE (2009) Declining coral calcification on the Great Barrier Reef. Science 323: 116-119

Denman K, Christian J, Steiner N, Pörtner HO, Nojiri Y (2011) Potential impacts of future ocean acidification on marine ecosystems and fisheries: present knowledge and recommendations for future research. ICES J Mar Sci 68: 1019-1029

Doucett RR, Booth RK, Power G, McKinley RS (1999) Effects of the spawning migration on the nutritional status of anadromous Atlantic salmon (Salmo salar): insights from stable-isotope analysis. Can J Fish Aquat Sci 56: 2172-2180

Eliason EJ, Clark TD, Hague MJ, Hanson LM and others (2011) Differences in thermal tolerance among sockeye salmon populations. Science 332:109-112

Eppley RW (1972) Temperature and phytoplankton growth in the sea. Fish Bull 70:1063-1085

- Farrell AP, Hinch SG, Cooke SJ, Patterson DA, Crossin GT, Lapointe M, Mathes MT (2008) Pacific salmon in hot water: applying aerobic scope models and biotelemetry to predict the success of spawning migrations. Physiol Biochem Zool 81:697-708

> Fernandez M, Bock C, Pörtner HO (2000) The cost of being a caring mother. Ecol Lett 3:487-494

> Findlay HS, Burrows MT, Kendall MA, Spicer JI, Widdicombe $S$ (2010) Can ocean acidification affect population dynamics of the barnacle Semibalanus balanoides at its southern range edge? Ecology 91:2931-2940

Harley CDG (2011) Climate change, keystone predation, and biodiversity loss. Science 334:1124-1127

Harley CDG, Helmuth BST (2003) Local- and regional-scale effects of wave exposure, thermal stress, and absolute versus effective shore level on patterns of intertidal zonation. Limnol Oceanogr 48:1498-1508

Hofmann AF, Peltzer ET, Walz PM, Brewer PG (2011) Hypoxia by degrees: establishing definitions for a changing ocean. Deep-Sea Res I 58:70-84

> Hoppe HG, Gocke K, Koppe R, Begler C (2002) Bacterial growth and primary production along a north-south transect of the Atlantic Ocean. Nature 416:168-171

Jones SJ, Mieszkowska N, Wethey DS (2009) Linking thermal tolerances and biogeography: Mytilus edulis (L.) at 
its southern limit on the east coast of the United States. Biol Bull (Woods Hole) 217:73-85

- Kassahn KS, Crozier RH, Pörtner HO, Caley MJ (2009) Animal performance and stress: responses and tolerance limits at different levels of biological organisation. Biol Rev Camb Philos Soc 84:277-292

Katsikatsou M, Anestis A, Pörtner HO, Vratsistas A, Aligizaki K, Michaelidis B (2012) Field studies and projections of climate change effects on the bearded horse mussel Modiolus barbatus in the Gulf of Thermaikos, Greece. Mar Ecol Prog Ser 449:183-196

Knoll AH, Fischer WW (2011) Skeletons and ocean chemistry: the long view. In: Gattuso JP, Hansson L (eds) Ocean acidification. Oxford University Press, Oxford, p 67-82

Knoll AH, Bambach RK, Canfield DE, Grotzinger JP (1996) Comparative earth history and Late Permian mass extinction. Science 273:452-457

Knoll AH, Bambach RK, Payne JL, Pruss S, Fischer WW (2007) Paleophysiology and end-Permian mass extinction. Earth Planet Sci Lett 256:295-313

Lannig G, Cherkasov AS, Pörtner HO, Bock C, Sokolova IM (2008) Cadmium-dependent oxygen limitation affects temperature tolerance in eastern oysters (Crassostrea virginica Gmelin). Am J Physiol 294:1338-1346

- Lucassen M, Koschnick N, Eckerle LG, Pörtner HO (2006) Mitochondrial mechanisms of cold adaptation in cod (Gadus morhua) populations from different climatic zones. J Exp Biol 209:2462-2471

Lurman GJ, Bock CH, Pörtner HO (2007) An examination of the metabolic processes underpinning critical swimming in Atlantic cod (Gadus morhua) using in vivo ${ }^{31} \mathrm{P}-\mathrm{NMR}$ spectroscopy. J Exp Biol 210:3749-3756

Marshall DJ, Dong Y, McQuaid CD, Williams GA (2011) Thermal adaptation in the intertidal snail Echinolittorina malaccana contradicts current theory by revealing the crucial roles of resting metabolism. J Exp Biol 214: 3649-3657

McCulloch M, Falter J, Trotter J, Montagna P (2012) Coral resilience to ocean acidification and global warming through pH up-regulation. Nat Clim Change 2:623-627

Metzger R, Sartoris FJ, Langenbuch M, Pörtner HO (2007) Influence of elevated $\mathrm{CO}_{2}$ concentrations on thermal tolerance of the edible crab Cancer pagurus. J Therm Biol 32:144-151

> Munday PL, Crawley NE, Nilsson GE (2009) Interacting effects of elevated temperature and ocean acidification on the aerobic performance of coral reef fishes. Mar Ecol Prog Ser 388:235-242

> Neuheimer AB, Thresher RE, Lyle JM, Semmens JM (2011) Tolerance limit for fish growth exceeded by warming waters. Nat Clim Change 1:110-113

Newell RC (1969) Effect of fluctuations in temperature on the metabolism of intertidal invertebrates. Am Zool 9: 293-307

> Peck LS, Clark MS, Morley SA, Massey A, Rossetti H (2009) Animal temperature limits and ecological relevance: effects of size, activity and rates of change. Funct Ecol 23: 248-256

> Perry AL, Low PJ, Ellis JR, Reynolds JD (2005) Climate change and distribution shifts in marine fishes. Science 308:1912-1915

> Pincebourde S, Sanford E, Helmuth B (2008) Body temperature during low tide alters the feeding performance of a top intertidal predator. Limnol Oceanogr 53:1562-1573
Pörtner HO (1982) Biochemische und physiologische Anpassungen an das Leben im marinen Sediment: Untersuchungen am Spritzwurm Sipunculus nudus L. PhD thesis, University of Düsseldorf

> Pörtner HO (2001) Climate change and temperaturedependent biogeography: oxygen limitation of thermal tolerance in animals. Naturwissenschaften 88:137-146

> Pörtner HO (2002a) Climate variations and the physiological basis of temperature dependent biogeography: systemic to molecular hierarchy of thermal tolerance in animals. Comp Biochem Physiol A Mol Integr Physiol 132:739-761

> Pörtner HO (2002b) Environmental and functional limits to muscular exercise and body size in marine invertebrate athletes. Comp Biochem Physiol A Mol Integr Physiol 133:303-321

Pörtner HO (2004) Climate variability and the energetic pathways of evolution: the origin of endothermy in mammals and birds. Physiol Biochem Zool 77:959-981

Pörtner HO (2006) Climate dependent evolution of Antarctic ectotherms: an integrative analysis. Deep-Sea Res II 53: 1071-1104

Pörtner HO (2008) Ecosystem effects of ocean acidification in times of ocean warming: a physiologist's view. Mar Ecol Prog Ser 373:203-217

> Pörtner HO (2010) Oxygen and capacity limitation of thermal tolerance: a matrix for integrating climate related stressors in marine ecosystems. J Exp Biol 213:881-893

> Pörtner HO, Farrell AP (2008) Physiology and climate change. Science 322:690-692

Pörtner HO, Knust R (2007) Climate change affects marine fishes through the oxygen limitation of thermal tolerance. Science 315:95-97

Pörtner HO, Lannig G (2009) Oxygen and capacity limited thermal tolerance. In: Richards JG, Farrell AP, Brauner CJ (eds) Fish physiology, Vol 27. Hypoxia. Academic Press, Burlington, MA, p 143-191

Pörtner HO, Branco LGS, Malvin GM, Wood SC (1994) A new function for lactate in the toad Bufo marinus. J Appl Physiol 76:2405-2410

Pörtner HO, Reipschläger A, Heisler N (1998) Metabolism and acid-base regulation in Sipunculus nudus as a function of ambient carbon dioxide. J Exp Biol 201:43-55

> Pörtner HO, Bock C, Reipschläger A (2000) Modulation of the cost of pHi regulation during metabolic depression: a ${ }^{31} \mathrm{P}-\mathrm{NMR}$ study in invertebrate (Sipunculus nudus) isolated muscle. J Exp Biol 203:2417-2428

Pörtner HO, Langenbuch M, Reipschläger A (2004a) Biological impact of elevated ocean $\mathrm{CO}_{2}$ concentrations: lessons from animal physiology and earth history. J Oceanogr 60:705-718

Pörtner HO, Mark FC, Bock C (2004b) Oxygen limited thermal tolerance in fish? Answers obtained by Nuclear Magnetic Resonance techniques. Respir Physiol Neurobiol 141:243-260

> Pörtner HO, Peck LS, Somero GN (2007) Thermal limits and adaptation: an integrative view. Philos Trans R Soc Lond B Biol Sci 362:2233-2258

> Pörtner HO, Bock C, Knust R, Lannig G, Lucassen M, Mark FC, Sartoris FJ (2008) Cod and climate in a latitudinal cline: physiological analyses of climate effects in marine fishes. Clim Res 37:253-270

Pörtner HO, Schulte PM, Wood CM, Schiemer F (2010) Niche dimensions and limits in fishes: an integrative view. Illustrating the role of physiology in understanding ecological realities. Physiol Biochem Zool 83:808-826 
Pörtner HO, Gutowska M, Ishimatsu A, Lucassen M, Melzner F, Seibel B (2011) Effects of ocean acidification on nektonic organisms. In: Gattuso JP, Hansson L (eds) Ocean acidification. Oxford University Press, Oxford, p 154-175

Pörtner HO, Peck LS, Somero GN (2012) Mechanisms defining thermal limits and adaptation in marine ectotherms: an integrative view. In: Rogers $\mathrm{AD}$, Johnston NM, Murphy EJ, Clarke A (eds) Antarctic ecosystems: an extreme environment in a changing world, 1st edn. Blackwell Publishing, Oxford, p 360-396

Ratkowsky DA, Lowry RK, McMeekin TA, Stokes AN, Chandler RE (1983) Model for bacterial culture growth rate throughout the entire biokinetic temperature range. J Bacteriol 154:1222-1226

Reipschläger A, Pörtner HO (1996) Metabolic depression during environmental stress: the role of extra- versus intracellular $\mathrm{pH}$ in Sipunculus nudus. J Exp Biol 199: 1801-1807

Reipschläger A, Nilsson GE, Pörtner HO (1997) A role for adenosine in metabolic depression in the marine invertebrate Sipunculus nudus. Am J Physiol 272:R350-R356

Sanford E, Kelly MW (2011) Local adaptation in marine invertebrates. Annu Rev Mar Sci 3:509-535

Schröer M, Wittmann AC, Grüner N, Steeger HU, Bock C, Paul R, Pörtner HO (2009) Oxygen limited thermal tolerance and performance in the lugworm Arenicola marina: a latitudinal comparison. J Exp Mar Biol Ecol 372:22-30

Schulte PM, Healy TM, Fangue NA (2011) Thermal performance curves, phenotypic plasticity, and the time scales of temperature exposure. Integr Comp Biol 51: 691-702

Seidl MD, Pirow R, Paul RJ (2005) Acclimation of the microcrustacean Daphnia magna to warm temperatures is dependent on haemoglobin expression. J Therm Biol 30: 532-544

Sokolova IM, Lannig G (2008) Interactive effects of metal pollution and temperature on metabolism in aquatic ectotherms: implications of global climate change. Clim Res 37:181-201

Sokolova IM, Frederich M, Bagwe R, Lannig G, Sukhotin AA (2012) Energy homeostasis as an integrative tool for assessing limits of environmental stress tolerance in aquatic invertebrates. Mar Environ Res 79:1-15

Somero GN (2012) The physiology of global change: linking patterns to mechanisms. Annu Rev Mar Sci 4:39-61

Stillman JH (2003) Acclimation capacity underlies susceptibility to climate change. Science 301:65

Sotka EE (2012) Natural selection, larval dispersal, and the geography of phenotype in the sea. Integr Comp Biol 52: $538-545$

Storch D, Santelices P, Barria J, Cabeza K, Pörtner HO, Fer-

Submitted: December 1, 2011; Accepted: October 18, 2012 nández M (2009) Temperature tolerance of crustacean larvae (zoea I) in two different populations of the kelp crab Taliepus dentatus (Milne-Edwards). J Exp Biol 212: 1371-1376

> Stramma L, Johnson GC, Sprintall J, Mohrholz V (2008) Expanding oxygen-minimum zones in the tropical oceans. Science 320:655-658

- Takasuka A, Oozeki Y, Aoki I (2007) Optimal growth temperature hypothesis: Why do anchovy flourish and sardine collapse or vice versa under the same ocean regime? Can J Fish Aquat Sci 64:768-776

Takasuka A, Oozeki Y, Kubota H (2008) Multi-species regime shifts reflected in spawning temperature optima of small pelagic fish in the western North Pacific. Mar Ecol Prog Ser 360:211-217

Taylor AR, Brownlee C, Wheeler G (2012) Proton channels in algae: reasons to be excited. Trends Plant Sci 17: 675-684

> Tewksbury JJ, Huey RB, Deutsch CA (2008) Ecologyputting the heat on tropical animals. Science 320: 1296-1297

> Thomas MK, Kremer CT, Klausmeier CA, Litchman E (2012) A global pattern of thermal adaptation in marine phytoplankton. Science 338:1085-1088

Tomanek L (2012) Environmental proteomics of the mussel Mytilus: implications for tolerance to stress and change in limits of biogeographic ranges in response to climate change. Integr Comp Biol 52:648-664

Verberk WCEP, Bilton DT (2011) Can oxygen set thermal limits in an insect and drive gigantism? PLoS ONE 6: e22610

> Walther K, Sartoris FJ, Bock C, Pörtner HO (2009) Impact of anthropogenic ocean acidification on thermal tolerance of the spider crab Hyas araneus. Biogeosciences 6: 2207-2215

> Wittmann A, Schröer M, Bock C, Steeger HU, Paul R, Pörtner HO (2008) Seasonal patterns of thermal tolerance and performance capacity in lugworm (Arenicola marina) populations in a latitudinal cline. Clim Res 37: $227-240$

Wittmann AC, Pörtner HO, Sartoris FJ (2012) A role for oxygen delivery and extracellular magnesium in limiting cold tolerance of the sub-Antarctic stone crab Paralomis granulosa? Physiol Biochem Zool 85:285-298

Woods HA, Moran AL (2008) Oxygen profiles in egg masses predicted from a diffusion-reaction model. J Exp Biol 211:790-797

Zittier ZMC, Hirse T, Pörtner HO (2012) The synergistic effects of increasing temperature and $\mathrm{CO}_{2}$ levels on exercise capacity and acid-base balance in the spider crab, Hyas araneus. Mar Biol, doi:10.1007/s00227-0122073-8

Proofs received from author(s): November 23, 2012 